\title{
Cytokine gene polymorphisms in inflammatory bowel disease
}

\author{
E Louis, J Satsangi, M Roussomoustakaki, M Parkes, G Fanning, K Welsh, D Jewell
}

\begin{abstract}
Background-Concordance rates in siblings and twins provide strong evidence that genetic susceptibility is important in the pathogenesis of inflammatory bowel disease. The number and identity of susceptibility genes is largely uncertain. Cytokine genes are attractive candidate loci.

Aims-To study allelic frequencies of polymorphisms of the interleukin-1 receptor antagonist (IL-1RA) gene and the tumour necrosis factor $\alpha$ gene in patients with inflammatory bowel disease.
\end{abstract}

Subjects-One hundred and twenty nine North European caucasoid patients with ulcerative colitis, 120 patients with Crohn's disease, and 89 healthy controls.

Methods-Genotyping was performed by polymerase chain reaction. A variable number of tandem repeats (VNTR) in the IL-1RA gene and a single base pair polymorphism in the TNF $\alpha$ gene promoter region (TNF-308) were analysed.

Results-No significant differences in IL-1RA VNTR allelic frequencies were noted between Crohn's disease (allele 1: $72 \cdot 6 \%$, allele 2: $24 \cdot 7 \%$, allele 3: $2 \cdot 6 \%$, ulcerative colitis $(72 \cdot 6 \%, 24 \cdot 3 \%, 3 \cdot 1 \%$, respectively), and controls $(76.9 \%, 20.8 \%$ and $2 \cdot 3 \%$ ). Some $42 \cdot 4 \%$ of patients with ulcerative colitis and $43.4 \%$ patients with Crohn's disease were carriers of allele 2, compared with $34 \cdot 8 \%$ healthy subjects. The TNF2 allele was modestly reduced in Crohn's disease $(13 \cdot 2 \%)$, compared with healthy subjects $(21 \cdot 3 \% ; p=0.04)$, and ulcerative colitis $(21 \cdot 6 \%)$.

Conclusions-The associations demonstrated are modest: these polymorphisms are unlikely to be important determinants of overall disease susceptibility.

(Gut 1996; 39: 705-710)

Keywords: Crohn's disease, ulcerative colitis, immunogenetics, cytokine gene polymorphisms.

Studies of the prevalence of familial inflammatory bowel disease have provided strong evidence that genetic susceptibility is important in the pathogenesis of both Crohn's disease and ulcerative colitis. ${ }^{1}$ For Crohn's disease in particular, the coefficient of heritability derived from disease concordance rates in twins $^{2}$ and siblings ${ }^{3}$ is greater than for asthma, rheumatoid disease or schizophrenia, and equivalent to that seen in insulin dependent diabetes mellitus.
Neither Crohn's disease nor ulcerative colitis has a monogenic mode of inheritance: it appears more likely that a combination of genetic and environmental influences are important determinants of disease susceptibility and phenotype. The inflammatory bowel diseases may consist of a heterogeneous group of disorders of polygenic inheritance. ${ }^{4}$ The number and identity of genes involved in disease susceptibility and phenotype has received considerable attention recently. Genes involved in the regulation of the immune response, particularly HLA class II genes, are strong candidates. Although studies have been complicated by ethnic differences, and disease heterogeneity, data from studies in Japan, ${ }^{5}$ California, ${ }^{6}$ Pittsburgh, ${ }^{7}$ and Western Europe ${ }^{8}$ together implicate genes in this region in the pathogenesis of ulcerative colitis.

This study evaluates the contribution of two other candidate genes with potential immunoregulatory activity in inflammatory bowel disease. The interleukin 1 receptor antagonist (IL-1RA) and tumour necrosis factor (TNF $\alpha$ ) have strong immunomodulatory activity. IL-1RA is a natural antagonist of the pro-inflammatory cytokine, interleukin 1. An imbalance in the production of interleukin 1 and IL-1RA has been demonstrated in patients with inflammatory bowel disease ${ }^{9}$; this may be important in the pathogenesis of chronic mucosal inflammation. The gene encoding the interleukin 1 receptor antagonist lies on chromosome 2 , and contains a polymorphic area within the second intron. ${ }^{10}$ This consists of a variable number of tandem repeats (VNTR) of an 86 base pair sequence. Five alleles are described; of these, allele 2 has been associated with ulcerative colitis, particularly extensive colitis, ${ }^{11}$ and other chronic inflammatory diseases. ${ }^{12}$ At present, the importance of this polymorphism in regulating IL-1RA production is under evaluation. $\mathrm{TNF} \alpha$ is a pro-inflammatory cytokine, implicated in the pathogenesis of both acute and chronic inflammatory disease. The gene encoding TNF $\alpha$ lies within the HLA class III region between the HLA class I and class II regions on the short arm of chromosome 6. A single base pair polymorphism in the promoter sequence $^{13}$ at residue-308 relative to the initiation site of gene transcription is of particular interest in inflammatory disease. In non-Jewish North European Caucasians, the less common TNF2 allele is in strong linkage disequilibrium with the HLA DR3 DQ2 haplotype, recently described to be a determinant of disease phenotype in ulcerative colitis. ${ }^{8}$ Furthermore, the TNF2 allele is associated with increased TNF $\alpha$ transcription, ${ }^{14}$ and has 
been implicated as a predictor of morbidity and mortality in cerebral malaria. ${ }^{15}$

\section{Methods}

SUBJECTS

Ethical approval for this study was given by the Central Oxford Research Ethics Committee in December 1992. Clinical data were obtained by questionnaire, review of case records and personal interview for all patients.

Patients with no family history of inflammatory bowel disease were selected at random from adult outpatients attending the gastroenterology clinics at the John Radcliffe Hospital in Oxford between January and November 1994. Patients with a family history of inflammatory bowel disease were chosen from our data base, which contains details of 250 multiply affected families throughout the United Kingdom. No two members from one family were included. In any family, the affected individual chosen was the first to develop disease.

The diagnosis of Crohn's disease or ulcerative colitis was made on the basis of clinical, radiological, and histological data, according to standard criteria. Patients with 'indeterminate' colitis were not studied. For both Crohn's disease and ulcerative colitis, disease phenotype was defined by sex, age of onset of symptoms, familial disease, disease extent, and need for surgery (as below).

Ethnic biases within the population studied have been minimised by excluding all Asians and south Europeans. The proportion of Jewish subjects amongst patients and controls is approximately $5 \%$.

\section{ULCERATIVE COLITIS PATIENTS}

A total of 129 adult patients with definite ulcerative colitis were studied (69 male; median age at presentation 32). Forty one patients had a positive family history of inflammatory bowel disease; 88 patients had no family history. Disease extent was defined by the proximal extent of disease at the most recent investigation performed (barium enema or colonoscopy). If macroscopic extent differed from microscopic assessment, the microscopic extent was recorded. Thus, extent was classified as extensive (inflammation proximal to the splenic flexure) in 63 patients and distal in 63 patients. In three patients, the extent of disease was uncertain. Seventeen patients had required colectomy for severe disease refractory to medical therapy. Five patients (three extensive, two distal) had primary sclerosing cholangitis.

CROHN'S DISEASE PATIENTS

One hundred and twenty unrelated patients with definite Crohn's disease (median age at presentation 25.0 years) were studied. Fifty were male and 45 patients had a positive family history of inflammatory bowel disease. Thirteen patients had predominantly fistulating disease,
31 stricturing disease, and 76 patients had predominantly inflammatory disease. Disease extent was defined on the basis of a combination of clinical, radiological, histological, and endoscopic evidence. Seventy three patients had both small and large bowel involvement, mainly ileocaecal disease. Patients with terminal ileal disease were included in this group. Thirty patients had exclusively colonic disease. Thirteen patients had exclusively jejunal or proximal ileal disease. In four patients, disease extent was uncertain. Sixty four patients had needed surgery for refractory disease (excluding perianal disease alone).

\section{CONTROLS}

Eighty nine unreleated European caucasoid individuals served as controls. These control subjects were either hospital workers or prospective blood donors. All were healthy Oxfordshire residents.

\section{DNA EXTRACTION}

Genomic DNA was extracted from $10 \mathrm{ml}$ venous blood using a modified 'salting out' technique, ${ }^{16}$ and resuspended in sterile distilled water at a final concentration of $0 \cdot 1-1 \cdot 0 \mu \mathrm{g} / \mu \mathrm{l}$, before use.

GENOTYPING

Genotyping for the cytokine gene polymorphisms was carried out using methodologies, involving the polymerase chain reaction.

Interleukin-1 receptor antagonist VNTR polymorphism (IL-1 RA VNTR) (Figure)

Primers specific for the polymorphism ${ }^{11}$ in intron 2 were used to amplify this region. The sense primer was 5'CTCAGCAACACTCCTAT3' and the antisense primer was 5'TCCTGGTCTGCAGGTAA3'. Amplification conditions were optimised by comparing the effects of a range of magnesium concentrations (1-2.5 mmol magnesium chloride) and annealing temperatures $\left(55^{\circ} \mathrm{C}\right.$ to $64^{\circ} \mathrm{C}$ ). The final conditions chosen for each individual DNA sample were those under which non-specific binding was minimised. At all conditions tested in this optimisation procedure, including those originally described, ${ }^{10}$ the amplification of allele 1 in heterozygotes was stronger than the amplification of the other alleles. The final conditions chosen involved 30 cycles of amplification in MJ Research 96V machines, each cycle consisting of 60 seconds at $94^{\circ} \mathrm{C}, 60$ seconds at $60^{\circ} \mathrm{C}$, and 60 seconds at $70^{\circ} \mathrm{C}$. The reaction mix $(25 \mu \mathrm{l})$ contained $1 \mu \mathrm{l}$ DNA, 1.5 mmol-2 mmol magnesium chloride, $67 \mathrm{mmol}$ TRIS base pH 8.8, $16.6 \mathrm{mmol}$ ammonium sulphate, $0.01 \%$ (v/v) TWEEN-20, $200 \mu \mathrm{mol}$ each dNTP, $0.025 \mathrm{U}$ Taq polymerase, and 1-3 mmol primers. Under these conditions, 228 patients $(92 \%)$ and 89 control subjects were accurately genotyped. Results from samples from the other 21 patients $(8 \%)$ 


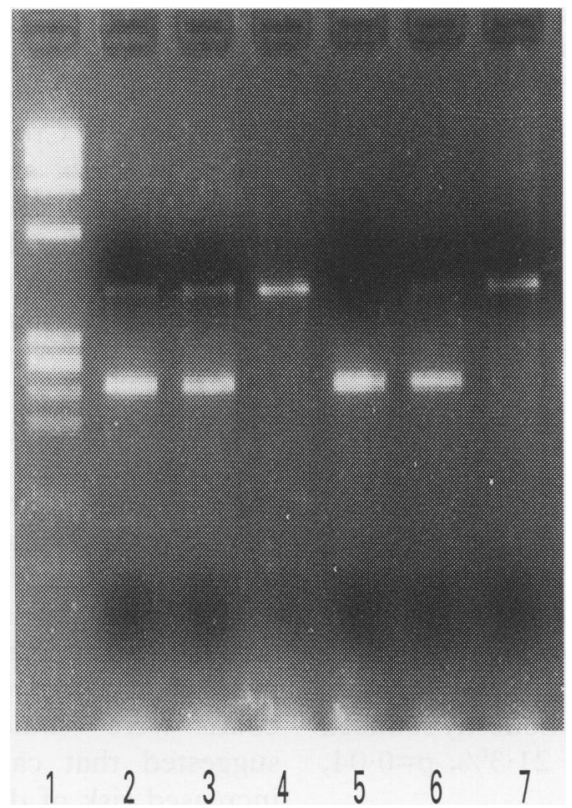

IL-1RA polymorphism. Amplified DNA from six individuals analysed on a $1 \%$ agarose gel stained with ethidium bromide. Lane 1 contains a standard DNA ladder. Individuals in lanes 4 and 7 are homozygous for allele 1 (410 base pairs); the individual in lane 5 is homozygous for allele 2 (240 base pairs); and the individuals in lanes 2 and 3 are heterogygous for alleles 1 and 2. The less common allele 3 (500 base pairs) is not shown.

were considered uncertain after three attempts at genotyping. These 21 patients were not included in the final data analysis.

TNF $\alpha-308$ single base pair substitution

As described by Verjans ${ }^{17}$ and colleagues, a method involving primers specific for each allele of the $G$ to A polymorphism at residue308 was used. Four primers were used: the $3^{\prime}$ primer 9C1, position -144/-164 5'-TCTCGGTTTCTTCTCCATCG-3') was used in combination with either the 5 ' primer $\mathrm{C} 2$ (position -328/-308G: 5'ATAGGTTTTGAGGGGCATGG-3'), complementary to the TNF- $\alpha 1$ allele (TNF1), or the 5 ' primer C3 $(-328 /-308 A$ : 5'ATAGGTTTTGAGGGGCATG $A-3^{\prime}$ ) which is complementary to the TNF- $\alpha 2$ allele (TNF2).

For each DNA sample, two parallel reactions were performed. The primer pair C1/C2 were used to produce specific amplification of TNF1; C1/C3 were used to amplify the TNF2 allele. As an internal control, primer D (position -675 to -655 : 5'GAGTCTCCGGGTCAGAATGA3') was added to each reaction. Amplification was carried out using the cycling conditions previously described. ${ }^{16}$

Ninety two per cent of patient samples were successfully genotyped; in $8 \%$ of samples, amplification was unsuccessful (either because of inadequate DNA, or non-specific amplification). Five cell lines homozygous for the TNF2 allele were also genotyped, to validate the methodology used.

After amplification, DNA samples were electrophoresed in $1 \%$ agarose gels containing ethidium bromide, and visualised under ultraviolet light.

STATISTICS

Allelic frequencies between groups were made using a $2 \times 2$ contingency table and $\chi^{2}$ statistics. Corrections were made where necessary for small sample numbers, using Fisher's exact test.

For subgroup analysis, correction was made for the multiple comparisons, taking into account the number of clinically defined parameters considered (age of onset, disease extent, need for surgery, sex, familial or nonfamilial). Thus probability values were multiplied by a factor of 5 to obtain corrected probability values.

A probability value, after correction if necessary, of 0.05 was considered to be the threshold for statistical significance.

\section{Results}

IL-1RA VNTR POLYMORPHISM

Allelic frequencies were measured in 113 of the patients with ulcerative colitis, 115 of the patients with Crohn's disease, and 89 healthy controls. No significant differences between groups were noted (Table I). Thirty one (35\%) healthy subjects, $48(42 \%)$ patients with ulcerative colitis, and $50(43 \%)$ patients with Crohn's disease were carriers of at least one copy of allele 2 (no significant differences).

Six healthy subjects $(7 \%)$, seven patients with ulcerative colitis $(6 \%)$, and seven patients with Crohn's disease $(6 \%)$ were homozygous for allele 2 .

On subgroup analysis, no association between allelic frequency, and groups defined by sex, age of onset, extent, need for surgery or familiality was present in ulcerative colitis or in Crohn's disease (Table II).

Twenty three of 57 patients $(40 \%)$ with extensive colitis and 25 of 55 patients $(45 \%)$

TABLE I IL-1RA VNTR polymorphism in inflammatory bowel disease: allelic frequencies (\%)

\begin{tabular}{|c|c|c|c|}
\hline & Allele 1 & Allele 2 & Allele 3 \\
\hline \multirow{3}{*}{$\begin{array}{l}\text { Ulcerative colitis } \\
\text { (113 patients) } \\
\text { Crohn's disease } \\
\text { (115 patients) } \\
\text { Controls } \\
\text { (89 subjects) }\end{array}$} & $72 \cdot 6$ & $24 \cdot 3$ & $3 \cdot 1$ \\
\hline & $72 \cdot 6$ & $24 \cdot 7$ & $2 \cdot 6$ \\
\hline & 76.9 & $20 \cdot 8$ & $2 \cdot 3$ \\
\hline
\end{tabular}

No significant differences in allelic frequencies were present in ulcerative colitis or Crohn's disease, compared with healthy subjects.

TABLE II IL-1RA VNTR polymorphism: allelic frequencies (\%) in extensive and distal ulcerative colitis

\begin{tabular}{|c|c|c|c|}
\hline & Allele 1 & Allele 2 & Allele 3 \\
\hline \multirow{3}{*}{$\begin{array}{l}\text { Ulcerative colitis } \\
\text { (113 patients) } \\
\text { Distal colitis } \\
\text { ( } 55 \text { patients) } \\
\text { Extensive colitis } \\
\text { (57 patients) }\end{array}$} & $72 \cdot 6$ & $24 \cdot 3$ & $3 \cdot 1$ \\
\hline & $71 \cdot 0$ & $25 \cdot 5$ & $3 \cdot 6$ \\
\hline & $73 \cdot 7$ & $23 \cdot 7$ & $2 \cdot 6$ \\
\hline
\end{tabular}

No significant difference in allele 2 carrier frequency or homozygosity was noted between extensive and distal disease. 
TABLE III TNF $\alpha$ polymorphism in inflammatory bowel disease: allelic frequency of TNF1 and TNF2

\begin{tabular}{lll}
\hline & $T N F 1$ & $T N F 2$ \\
\hline Ulcerative colitis (118 patients) & $78 \cdot 4$ & $21 \cdot 6$ \\
Crohn's disease (110 patients) & $86 \cdot 8^{1}$ & $13 \cdot 2$ \\
Healthy subjects (89 subjects) & $78 \cdot 7^{\star}$ & $21 \cdot 3$ \\
\hline${ }^{\star} \mathrm{p}=0 \cdot 04 ; \chi^{2}=4 \cdot 12$. & &
\end{tabular}

with distal disease were carriers of at least one copy of allele 2 .

TNF $\alpha$ POLYMORPHISM

One hundred and eighteen of the patients with ulcerative colitis, 110 of the patients with Crohn's disease, and 89 healthy subjects were successfully genotyped: allelic frequencies are given in Table III. Compared with healthy subjects, the TNF2 allele was modestly reduced in Crohn's disease $(13.2 \%$ v 21.3\%, $\mathrm{p}=0.04$, $\left.\chi^{2}=4 \cdot 12\right)$.

No difference between groups in TNF2 carrier frequency was evident. Three patients (3\%) with ulcerative colitis (one distal, two extensive), one patient with Crohn's disease $(0.9 \%)$, and five controls $(6 \%)$ were homozygous for the TNF2 allele.

On subgroup analysis, allelic frequency was compared with sex, age of onset, extent of disease, and need for surgery. No significant difference between subgroups was evident in Crohn's disease. In ulcerative colitis, differences were noted only when patients with distal disease were also stratified by sex (Table IV).

TNF2 allelic frequency was compared with the frequency of the DRB $1{ }^{\star} 0301 \mathrm{DQB} 1{ }^{\star} 0201$ haplotype in 118 patients with ulcerative colitis and 110 patients with Crohn's disease ${ }^{8}$; as expected, the observed allelic frequencies strongly suggested the TNF2 allele to be in linkage disequilibrium with the $\mathrm{DRB} 1{ }^{\star} 0301$ DQB $1^{\star} 0201$ haplotype $\left(p=0.000002, \chi^{2}=37 \cdot 47\right)$.

\section{Discussion}

Alterations in the production of cytokines, including $\mathrm{TNF} \alpha$ and cytokines of the interleukin 1 family, are well described in inflammatory bowel disease. However, the significance of these findings in the pathogenesis of Crohn's disease and ulcerative colitis remains poorly understood: controversy continues as to whether these changes represent a primary defect in the regulation of the immune system, or a secondary consequence of immune activation.

The results of this study provide no evidence that the polymorphism in intron- 2 of the IL-

TABLE IV TNF $\alpha$ polymorphism in ulcerative colitis: allelic frequency (\%) in extensive and distal colitis

\begin{tabular}{lll}
\hline & TNF1 & TNF2 \\
\hline Extensive colitis $(\mathrm{n}=58)$ & $80 \cdot 0$ & $20 \cdot 0$ \\
Distal colitis $(\mathrm{n}=58)$ & $81 \cdot 0$ & $19 \cdot 0$ \\
Distal male $(\mathrm{n}=29)$ & $72 \cdot 4$ & $27 \cdot 6$ \\
Distal female $(\mathrm{n}=29)$ & $89 \cdot 7$ & $10 \cdot 3$ \\
\hline
\end{tabular}

Differences between women and men with distal colitis were significant before correction for multiple comparisons $(p=0.022)$, but not after correction.
1RA gene is primarily involved in the pathogenesis of Crohn's disease or ulcerative colitis. Allelic frequencies were similar in patients with Crohn's disease and ulcerative colitis, and not significantly greater than the control population. Although a slightly higher proportion of inflammatory bowel disease patients (both Crohn's disease and ulcerative colitis) were carriers of allele 2 , compared with controls, the differences did not attain significance.

The results of this study may be compared with recent data from the UK, Western Europe, and North America. The initial work from Sheffield ${ }^{11}$ had proposed that allele 2 of the IL-1RA gene was associated with ulcerative colitis $(35 \% v 24 \%$ in controls, $\mathrm{p}=0.007)$. The association appeared strongest in extensive disease, although only 18 patients with total colitis were studied. The same study also suggested that carriers of allele 2 were at increased risk of developing ulcerative colitis. Subsequent studies from Holland ${ }^{18}$ and Germany $^{19}$ of North European non-Jewish populations, have demonstrated, as in this study, an increase in allele 2 carriage rate in patients with ulcerative colitis compared with local controls, but the differences were not significant. Furthermore, those studies were unable to confirm an increase in frequency of allele 2 in ulcerative colitis.

Two studies have recently been performed in the United States, involving Hispanic residents in Los Angeles ${ }^{20}$ and a mixed Jewish-nonJewish $^{21}$ Pittsburgh population. The data are, as yet, in abstract form only. In both cities, allele 2 carriage was significantly increased in ulcerative colitis.

The explanation for the differences between all these recent studies is unclear. All have involved the same primers for genotyping. Ethnic differences, which have been largely responsible for many controversies in interpreting HLA association studies in Crohn's disease and ulcerative colitis, do not appear pertinent to the studies performed in Europe, but exist in the American data.

Sampling differences, and disease heterogeneity may be most relevant. There is considerable interest in the concept of heterogeneity within ulcerative colitis. Recent data from Oxford ${ }^{8}$ have demonstrated that different HLA class II alleles are implicated in extensive and distal colitis. Similarly, if allele 2 of the IL1RA is exclusively associated with only a particular phenotype of ulcerative colitis, which was represented in the patients from Sheffield, but not those from Oxford, this may contribute to the discrepancies between the two studies. However the subclassification of ulcerative colitis by phenotype is particularly difficult and controversial. Extent of disease in an individual patient changes over time such that distal disease may become extensive and, likewise, extensive disease may regress. ${ }^{22}$ Further studies are in progress in Oxford to examine the frequencies of alleles of the IL1RA polymorphism in severe colitis requiring colectomy, and in patients developing recurrent inflammation of the ileoanal pouch 
(pouchitis). ${ }^{23}$ In those patients, the extent of disease can be defined very precisely, at least at the time of their operation. It is possible that patients carrying allele 2 of IL-1RA may have extensive disease at onset and may show no regression over time, but only prospective longitudinal studies involving newly diagnosed patients will be able to answer this.

The functional importance of the IL-1RA polymorphism has recently been considered. Danis and colleagues ${ }^{24}$ have demonstrated a relation between phenotype and genotype. Using human peripheral blood mononuclear cells stimulated by granulocyte-macrophage colony stimulating factor, stable interindividual variations were present. Homozygotes for, and heterozygote carriers of allele 2 were shown to have an increased ability to produce IL-1RA and a decreased ability to produce interleukin $1 \alpha$. These data were particularly interesting since the VNTR polymorphism of IL-1RA is in intron-2 and therefore in a non-coding part of the gene.

Polymorphisms of the TNF $\alpha$ gene, particularly the single base pair substitution at residue -308 of the promoter region, have become the focus of great interest in immune mediated disease. The TNF2 allele has been shown not only to be in strong linkage disequilibrium with the 'autoimmune' HLA A1 DR DQ2 haplotype, but also may be implicated in the regulation of $T N F \alpha$ transcription. Using reporter gene constructs, Wilson and colleagues ${ }^{14}$ have demonstrated a sixfold to sevenfold higher level of transcription from TNF2 compared with TNF1 in unstimulated and PMA stimulated Raji cells. Data relating genotype with $\mathrm{TNF} \alpha$ production from peripheral blood mononuclear cells are awaited. This study provides some limited evidence that the TNF $\alpha$ gene, or linked genes in the HLA region are involved in determining susceptibility and disease phenotype in inflammatory bowel disease. Modest decreases in the frequency of the TNF2 allele were noted in Crohn's disease and in female patients with distal colitis. Although the reduction in TNF2 allele frequency may be somewhat surprising in view of the high TNF $\alpha$ production associated with active inflammatory bowel disease, these results are in keeping with recent class II association data reported from Oxford. The DR3 DQ2 haplotype was shown to be reduced in women with distal colitis, and in patients with colonic Crohn's disease. ${ }^{8} \mathrm{~A}$ number of studies are currently in progress to clarify the importance of the class II and class III HLA genes in the pathogenesis of inflammatory bowel disease. Microsatellite markers in the $\mathrm{TNF} \alpha$ region are likely to be informative in future linkage and association studies. ${ }^{25}$

Overall, the associations demonstrated between cytokine gene polymorphisms and Crohn's disease and ulcerative colitis are limited in this study: it appears unlikely that these loci are important overall determinants of disease susceptibility. Further studies will be required to determine whether these polymorphisms affect disease behaviour. The contribution of other genes is worthy of investi- gation. Approaches involving other candidate genes $^{4}$ and systematic genome screening ${ }^{26}$ are practicable, and in progress in centres in Europe and the United States.

Jack Satsangi is a Medical Research Council Training Fellow. Edouard Louis is supported by a grant from the Rotary Club of Liege, Belgium. Edouard Louis and Jack Satsangi contributed equally to this study.

Note added in proof: Since the initial submission of this paper in October 1995, a number of authors have published data concerning the functional effect of these cytokine polymorphisms (Bourma et al, Clin Exp Immunol 1996; 103: 391-6, Brinkman et al, $\mathcal{F}$ Inflamm 1996; 46: 32-41).

1 McConnell RB, Vadheim CM. Inflammatory bowel disease. In: King RA, Rotter JI, Motulsky AO, ed. The genetic basis of common diseases. Oxford: Oxford University Press, 1992: 326-48.

2 Tysk C, Lindberg E, Järnerot G, Flodérus-Myrhed B. Ulcerative colitis and Crohn's disease in an unselected population of monozygotic and dizygotic twins. A study of heritability and the influence of smoking. Gut 1988; 28: 990-6.

3 Satsangi J, Rosenberg WMC, Jewell DP. The prevalence of inflammatory bowel disease in relatives of patients with Crohn's disease. Eur $\mathcal{f}$ Gastroenterol Hepatol 1994; 6: 413-6.

4 Satsangi J, Jewell DP, Rosenberg WMC, Bell JI. Genetics of inflammatory bowel disease. Gut 1994; 35: 696-700.

5 Asakura H, Tsuchiya M, Aiso S, et al. Association of human leucocyte DR2 antigen with Japanese ulcerative colitis. Gastroenterology 1982; 82: 413-8.

6 Toyoda H, Wang S-J, Yang H, Redford A, Magalong D, Tyan $\mathrm{D}$, et al. Distinct association of HLA class II genes with inflammatory bowel disease. Gastroenterology 1993; 104: 741-8.

7 Duerr RH, Neigut DA. Molecularly defined HLA-DR2 alleles in ulcerative colitis and an anti-neutrophil cytoplasmic antibody-positive subgroup. Gastroenterology 1995; 108: 423-7.

8 Satsangi J, Welsh KI, Bunce M, et al. Contribution of genes of the major histocompatibility complex to susceptibility of the major histocompatibility complex to susceptibility and disease phenotype in

9 Casini-Raggi V, Kam L, Chong YJ, Fiocchi C, Pizarro TT, Cominelli F. Mucosal imbalance of IL-1 and IL-1 receptor antagonist in inflammatory bowel disease. A novel mechanism of chronic intestinal inflammation. f Immunol 1995; 154: 2434-40.

10 Tarlow JK, Blakemore AIF, Lennard A, et al. Polymorphism in human IL-1 receptor antagonist gene intron 2 is caused by variable numbers of an $86-\mathrm{bp}$ tandem repeat. Hum Genet 1993; 9: 403-4.

11 Mansfield JC, Holden $\mathrm{H}$, Tarlow JK, et al. Novel genetic association between ulcerative colitis and the antiassociation between ulcerative colitis and the antiinflammatory cytokine interleukin-1

12 Tarlow JK, Blakemore AIF, Cork MJ, Messenger A, McDonagh A, Bleehen SS. Association between interleukin-1 receptor antagonist (IL1-RA) gene polymorphism and chronic inflammatory diseases. Lymphokine Cytokine Research 1993; 12: A181.

13 Wilson AG, de Vries N, Pociot F, de Giovine FS, Van Der Putte LBA, Duff GW. An allelic polymorphism within the human tumour necrosis factor-alpha promoter region is strongly associated with HLA A1, B8 and DR3 alleles. f Exp Med 1993; 177: 557-60.

14 Wilson AG, Symons JA, McDowell TL, di Giovine FS, Duff GW. Effects of a tumour necrosis factor- $\alpha$ (TNF- $\alpha$ ) promoter base transition on transcriptional activity. $B r \mathcal{F}$ promoter base transition

15 McGuire W, Hill AVS, Allsopp CEM, Greenwood BM, Kwiatkovski D. Variation in the TNF- $\alpha$ promoter region associated with susceptibility to cerebral malaria. Nature 1994; 371: 508-11.

16 Bunce M, Taylor CJ, Welsh KI. Rapid HLA-DQB typing by eight PCR amplifications with sequence-specific primers (PCR-SSP). Hum Immunol 1993; 37: 201-6.

17 Verians GMGM, Brinkman BMN, van Doornik CEM, Kijlstra A, Verweij CL. Polymorphism of tumour necrosis factor- $\alpha$ (TNF- $\alpha$ ) at position -308 in relation to factor- $\alpha$. $(1 N F-\alpha)$ at position -308 in relation to ankylosing spondylitis. Clin Exp Immunol 1994; 97: 45-7. oque G, Monteleone G, Crusius JBA, et al. Further evidence for a genetic association of interleukin-1 receptor antagonist with ulcerative colitis in a Northern and a Mediters.

19 Andus T, Caesar I, Vogl D, Scholmerich J, Gross V. Association of HLA-DR15, pANCA and IL-1 receptor antagonist allele 2 with ulcerative colitis. Gastroenterology 1995; 108: A770.

20 Tountas NA, Kam L, di Giovine FS, Casini-Raggi V, Cominelli F. Genetic association between allele 2 of IL-1 receptor antagonist (IL-1RA) and ulcerative colitis in a Los Angeles based Hispanic population. Gastroenterology 1995; 108: A930.

21 Duerr RH, Tran T. Association between ulcerative colitis and a polymorphism in intron 2 of the interleukin-1 receptor antagonist gene. Gastroenterology 1995; 108: A812. 
22 Langholz E, Nielsen $\mathrm{OH}$, Munkholm P, Davidsen $M$, Binder V. Course and prognostic factors influencing anatomical extent of ulcerative colitis. Gastroenterology 1995; 108: A857.

23 Roussomoustakaki M, Louis E, Satsangi J, Mortensen NJM, Kettlewell MGW, Jewell DP. Cytokine gene polymorphisms in patients with an ileal pouch anal anastomosis (IPAA) for ulcerative colitis. Gut 1995; 37(suppl 2): A415.

24 Danis VA, Millington M, Hyland VJ, Grennan D. Cytokine production by normal human monocytes: inter-subject variation and relationship to an IL-1 receptor antagonist (IL-1RA) gene polymorphism. Clin Exp Immunol 1995;

25 Nedospasov SA, Udalova IA, Kujrash DV, Turetskayar RL. DNA sequence polymorphism at the human tumour necrosis factor (TNF) locus. $\mathcal{f}$ Immunol 1991; 147: 1053-9.

26 Weissenbach J, Gyapay G, Dib C, et al. A second generation linkage map of the human genome. Nature 1992; 359: 794-801. 